\title{
A brief Acceptance and Commitment Therapy-based intervention among violence-prone male inmates delivered by novice therapists
}

\author{
Nikolett EISENBECK*1, Katalin SCHEITZ** \& Boglárka SZEKERES** \\ (*) Universidad de Almería, Spain (**) Jász-Nagykun-Szolnok Megyei Büntetés-végrehajtási Intézet, Hungary.
}

(Received on August 2, 2016; Accepted on October 10, 2016)

\begin{abstract}
Acceptance and mindfulness-oriented cognitive and behavioral therapies, such as Acceptance and Commitment Therapy (ACT) are implemented in a wide range of different populations, but are not commonly used currently in correctional facilities. Objective: This study aimed to assess an intervention based on ACT in comparison with a treatment as usual condition (TAU) among inmates. Method: We compared 10 group sessions of ACT $(n=9)$ with TAU $(n=8)$ among male prisoners charged with violent crimes, administered by novice ACT therapists. Results: At postintervention, ACT was more effective in enhancing values-consistent behaviors than TAU as measured by the Valued Living Questionnaire. Depression, anxiety and psychological flexibility did not change after any of the treatments. These results were maintained at three-month follow-up. Conclusions: A brief ACT intervention delivered by inexperienced ACT therapists can be effective in increasing values-behavior consistency among male inmates. ACT may be a viable and cost-effective intervention alternative in penitentiary contexts.
\end{abstract}

Keywords: Acceptance and Commitment Therapy (ACT); inmates; novice therapists; short intervention.

Una intervención breve de Terapia de Aceptación y Compromiso en internos varones con propensión a la violencia llevada a cabo por terapeutas noveles

RESUMEN: Las terapias cognitivo-conductuales basadas en la aceptación y la atención plena, como la Terapia de Aceptación y Compromiso (ACT), se aplican en una amplia gama de poblaciones, pero su uso no es habitual en establecimientos penitenciarios. Objetivo: El presente estudio tuvo como objetivo evaluar una intervención basada en ACT en comparación con el tratamiento habitual (TH) entre internos de una prisión. Método: Se compararon 10 sesiones grupales de ACT $(n=9)$ con TH $(n=8)$, administradas por los terapeutas noveles a internos varones acusados de crímenes violentos. Resultados: Después de la intervención, ACT fue más eficaz que TH en mejorar los comportamientos basados en valores, medidos a través del Valued Living Questionnaire (Cuestionario de Valores). Los niveles de depresión, ansiedad y flexibilidad psicológica no cambiaron después de cualquiera de los tratamientos. Estos resultados se mantuvieron a los tres meses de seguimiento. Conclusiones: Una intervención breve de ACT, aplicada por terapeutas con poca experiencia, puede ser eficaz para aumentar la consistencia entre el comportamiento y los valores personales de internos masculinos. ACT puede ser una alternativa viable y rentable en contextos penitenciarios. 
Palabras clave: Terapia de Acepotación y Compromiso (ACT), internos, terapeutas nóveles, intervención breve.

Correspondence: Nikolett Eisenbeck, Edificio A de Humanidades, Universidad de Almería, 04120 Almería. eisenbeckniki@gmail.com.

Psychological problems are particularly common among inmates (e.g., James \& Glaze, 2006) and the prison environment itself (e.g., strict rules, reduced personal space and social support, etc.) is highly demanding. This is especially true in the early phases of imprisonment, which is a vulnerable period with a moderately high incidence of adjustment disorders (e.g., Andersen, 2004). Therefore, prison-based psychotherapeutic interventions are very challenging, sometimes with difficulties in achieving success (e.g., Andersen, 2004; Rice, Harris, \& Cormier, 1992). Nevertheless, data show that many prison-based cognitivebehavioral therapy (CBT) programs are at least partially effective in decreasing recidivism and possibly reducing psychological symptoms (e.g., Andrews et al., 1990; Khodayarifard, Shokoohi-Yekta, \& Hamot, 2010; Landenberger \& Lipsey, 2005; Lipsey, Landenberger, \& Wilson, 2007; Wilson, Bouffard, \& MacKenzie, 2005).

Acceptance and mindfulness-oriented cognitive and behavioral therapies may also be successful in penitentiary contexts, but data are scarce (e.g., mindfulness-based approaches: Bowen et al., 2006; Dialectical Behavior Therapy: Berzins \& Trestman, 2004). As compared to the traditional CBTs, these interventions do not aim to directly change unwanted thoughts or feelings, but seek to modify the person's relationship with them (see for instance: Hayes, Luoma, Bond, Masuda, \& Lillis, 2006; Hayes, Pistorello, \& Levin, 2012; Hayes, Strosahl, \& Wilson, 2011). Among these therapies, the most widely researched is the Acceptance and Commitment Therapy (ACT; Hayes, Strosahl, \& Wilson, 1999). According to ACT, the source of human suffering is the psychological inflexibility: attempts to control unwanted thoughts and feelings instead of living a life based on personal values (e.g., Hayes et al., 2006; Hayes et al., 1999). Thus, clinical work in ACT focuses on the development of a meaningful life while accepting inner experiences as they appear (e.g., Hayes et al., 2011). ACT seems to be at least as successful as habitual treatments across a variety of client populations and target problems (e.g., A-Tjak et al., 2015; Hayes et al., 2006; Öst, 2008; Öst, 2014; Powers, Zum Vörde Sive Vörding, \& Emmelkamp, 2009).

ACT may be suitable and effective in penitentiary contexts for a number of reasons. First, the target problems in ACT include those that are common in incarcerated populations, such as attempts to suppress or avoid any kind of emotional pain, lack of awareness in the present moment and lack of values-driven behaviors (Amrod \& Hayes, 2013). Second, interventions in correctional facilities are especially sensitive to time- and cost-efficacy (e.g., Harvey \& Smedley, 2010) and ACT-based treatments can be adapted to these special conditions. Its underlying transdiagnostic model (that psychological flexibility is the source of many psychological problems) combined with social support makes ACT optimal for group delivery, enabling a better use of the therapist's time (e.g., Hayes et al., 2011; Johns et al., 2015; Oliver, Joseph, Byrne, Johns, \& Morris, 2013). Moreover, ACT interventions are present and future focused and they can be successful even after only a few sessions (e.g., Bach \& Hayes, 2002; Kohtala, Lappalainen, Savonen, Timo, \& Tolvanen, 2015). Finally, ACT can be (c) Psy, Soc, \& Educ, 2015, Vol. 8(3) 
effective even when delivered by novice therapists (e.g., Forman, Herbert, Moitra, Yeomans, \& Geller, 2007; Kohtala et al., 2015; Lappalainen et al., 2007) and may help in stress management intervention of the therapists (e.g., Luoma \& Vilardaga, 2013; Stafford-Brown \& Pakenham, 2012)

Despite these considerations, there are only very limited data on ACT among inmates. For instance, a recent study compared ACT with CBT and a waitlist control among fifty incarcerated women with substance abuse disorder (full study: Lanza, García, Lamelas, \& González, 2014; partial data of the same study: Lanza \&González, 2013; González, García, Lamelas, \& Lanza, 2014). After 16 weekly group sessions, ACT was less effective than CBT in reducing anxiety sensitivity, but it was more successful in reducing drug use and improving mental health than CBT at 6-months and 18-months follow-up.

Nonetheless, it is still unknown whether ACT may be effective in correctional facilities when compared with other usual treatments, delivered by novice therapists or among male inmates. The latter may be especially relevant because most of the inmates are male and, besides drug use, many of them are charged for crimes against property or persons that often imply violent behavior (for European statistics, see Eurostat: Crime and criminal justice database, 2015). The present study represents the first research of ACT for male individuals in penitentiary contexts charged with violent crimes. It compares the effects of an ACT-based group intervention with a treatment as usual (TAU) group over ten weekly sessions delivered by novice ACT therapists.

\section{Method}

\section{Participants}

A total of 18 males in pre-trial detention signed up for the study. All of them had been detained for less than 12 months and were incarcerated in a state prison (Szolnok, Hungary). The inclusion criteria were the following: (1) to be charged for crimes that involved violence and (2) not to present serious mental illness (e.g., schizophrenia, self-harming tendencies). Inmates previously diagnosed with moderate levels of depression were included in the study. One participant was removed because he had attempted to commit suicide the previous year. The participants' age ranged from 18 to $41(M=26.47, S D=8.06)$ and were randomly assigned to one of the two conditions: ACT $(n=9)$ or TAU $(n=8)$.

\section{Measures}

All participants were given a battery of questionnaires prior to the start of the interventions, at post-intervention and at 3-month follow-up.

Acceptance and Action Questionnaire II (AAQ-II; Bond et al., 2011). The Hungarian version of the AAQ-II was implemented (Eisenbeck, Szondy, Schlosser, \& Szabo-Bartha, under preparation-a). The questionnaire includes 7 items to measure psychological flexibility: the ability to be fully in contact with the present moment and persist in or change behavior in pursuit of goals and values. Participants rate to what extent each statement is true for them, by using a 7-point Likert scale from 1 (never true) to 7 (always true). Total scores range from 7 to 
49, with higher scores indicating higher psychological inflexibility. The AAQ-II is a unidimensional measure, with high mean alpha coefficients (Bond et al., 2011) In the present study, Cronbach's alphas at pre-intervention, post-intervention and 3-month follow-up were $.86, .84$ and .89 , respectively.

Beck Depression Inventory-Short Form (BDI-SF; Beck \& Beck, 1972; Hungarian version by Rózsa, Szádóczky, \& Füredi, 2001). The short version of the BDI is a 13-item selfreport instrument that assesses the severity of depressive symptoms. Each item has four response options, scoring between 0 and 3. Total scores range between 0 and 39, with higher scores showing more severe depressive symptoms. The Hungarian version has demonstrated good internal consistency (Rózsa et al., 2001). In the present study, alphas were .83, .52 and .64 .

Beck Anxiety Inventory (BAI; Beck, Epstein, Brown, \& Steer, 1988; Hungarian version by Perczel Forintos, Sallai, \& Rózsa, 2001). The BAI comprises 21 items describing different anxiety symptoms. The participants rate how bothersome each symptom has been over the past week from 0 (not at all) to 3 (severely). Higher scores (up to 63) show greater levels of anxiety. Alphas typically are good (Perczel Forintos et al., 2001), they were .96, .94 and .97 in this study.

Valued Living Questionnaire (VLQ; Wilson, Sandoz, Kitchens, \& Roberts, 2011).The Hungarian version of this instrument is under preparation (Eisenbeck, Szondy, Schlosser, \& Szabo-Bartha, under preparation-b). The VLQ systematically assesses valued living, the extent to which a person is in contact with his or her chosen values. First, participants rate the importance of 10 life domains (such as family, work, friends, spirituality, etc.) on a 10-point Likert scale $(1=$ not at all important, $10=$ extremely important). After that, they rate from 1 (not at all consistent) to 10 (extremely consistent) to what degree they have consistently lived in accordance with their values within each domain over the past week. Internal consistencies are typically good (Wilson et al., 2011). In the present study, reliability data were .48, .32 and .87 for Importance scores and .82, .66 and .81 for Consistency scores.

\section{Procedure}

The study took place in a state prison in Szolnok, Hungary. All the procedures were reviewed and approved by the prison management team. All information was confidential and the questionnaires were administered individually. A total of 18 inmates responded to the announcements, 17 fulfilling the inclusion criteria. They were randomly assigned to one of the treatment conditions. (ACT: $n=9$; TAU: $n=9$ ). None of the participants discontinued the treatment voluntarily, but various participants were transferred to another correctional facility during the course of the study. Due to transfer, there were five participants available in each group at post-intervention. Four inmates remained in ACT and three in TAU at three-month follow-up.

Both interventions followed a treatment protocol and had a total of 10 weekly group sessions lasting 90 minutes per session. The interventions were carried out by a clinical psychologist and a social worker with extensive experience of prison-based interventions. They were supervised by a PhD-level researcher during the ACT intervention and by a clinical psychologist during the TAU intervention. The therapists had weekly supervision in order to 
properly monitor the process. As audio or video recordings were not allowed in the prison, the therapist provided feedback about their perceived adherence to the treatment protocols during supervision and the subsequent session was slightly modified if necessary. The completed treatment protocols are shown in Table 1. Detailed protocols are available upon request.

TAU treatment program. This program was based on cognitive-behavior therapy with elements of psychodrama, reflecting the clinical training and previous experience of the two therapists. It aimed to change the participants' behavior through acquiring coping skills: identifying and changing unwanted situations and problematic mental events.

ACT-based treatment program. The two therapists did not have prior knowledge of ACT and agreed to "try something different". First, they had a short, intensive training course of 15 contact hours with the first author of this article. After that, the treatment protocol was created and adapted to the target population using exercises and metaphors from a great variety of sources (e.g., Hayes et al., 1999; Hayes et al, 2012; Luciano et al., 2011; Segal, Williams, \& Teasdale, 2002;Wilson \& Luciano, 2002; etc.). The ACT intervention did not aim to eliminate symptoms of psychopathology or change unwanted thoughts and feelings. Instead, it introduced metaphors and exercises to help (1) to live according to one's personal values by connecting what is important for the person with everyday actions (direction of values) and (2) to learn not to take literally one's thoughts and feelings and as such, to create distance from them (defusion and mindfulness-related exercises). Home assignments were given after each session.

Table 1. Protocol of TAU and ACT per session

\begin{tabular}{|c|c|c|}
\hline & TAU & ACT \\
\hline Session 1 & $\begin{array}{l}\text { - } \quad \text { Rules of participation } \\
\text { - } \quad \text { Discussion about the main topics of the } \\
\text { - } \quad \text { sessions (stress, drugs, coping) } \\
\text {-introductions through drawings }\end{array}$ & $\begin{array}{l}\text { - } \quad \text { Rules of participation } \\
\text { - } \quad \text { Self-introductions } \\
\text { - Path up the Mountain and the Compass } \\
\text { Metaphor (see: Hayes et al., 1999, pp. } \\
222 \text { and 209) }\end{array}$ \\
\hline Session 2 & $\begin{array}{l}\text { - Psychoeducation about stress and } \\
\text { about different coping mechanisms }\end{array}$ & $\begin{array}{l}\text { - Work based on the Path up the } \\
\text { Mountain Metaphor (values-goals- } \\
\text { actions relationships) }\end{array}$ \\
\hline Session 3 & $\begin{array}{l}\text { - Scriptwriting about a chosen coping } \\
\text { mechanism } \\
\text { - Dramatic representation of the chosen } \\
\text { coping mechanism }\end{array}$ & $\begin{array}{l}\text { - Conversation about avoidance } \\
\text { behaviors and about controlling inner } \\
\text { experiences (e.g., Polygraph metaphor, } \\
\text { Hayes et al., 199, p.123) }\end{array}$ \\
\hline Session 4 & $\begin{array}{l}\text { - Replay of the story of the last session } \\
\text { with alternative endings } \\
\text { - Discussion about adaptive and } \\
\text { maladaptive coping mechanisms }\end{array}$ & $\begin{array}{l}\text { - Work with personal barriers (Imagining } \\
\text { them as loud birds while walking up } \\
\text { the mountain) } \\
\text { - Defusion exercises (e.g., Luciano et al., } \\
\text { 2011) }\end{array}$ \\
\hline Session 5 & $\begin{array}{l}\text { - Discussion about the effects of drug } \\
\text { abuse and its alternatives }\end{array}$ & - Overview of the previous exercises \\
\hline Session 6 & $\begin{array}{l}\text { - Conversation about the alternatives of } \\
\text { destructive behavior and drug abuse } \\
\text { - The role of self-awareness to recognize } \\
\text { risky situations }\end{array}$ & $\begin{array}{l}\text { - Personalized work with the birds and } \\
\text { the mountain metaphor }\end{array}$ \\
\hline
\end{tabular}




\begin{tabular}{|c|c|c|}
\hline Session 7 & $\begin{array}{l}\text { - Discussion and role-playing about } \\
\text { different types of communication }\end{array}$ & $\begin{array}{l}\text { - Focused breathing exercises in the } \\
\text { context of values (similar to Segal, } \\
\text { Williams, \& Teasdale, 2002, pp. 172- } \\
\text { 173) }\end{array}$ \\
\hline Session 8 & $\begin{array}{l}\text { - Conversation about their own positive } \\
\text { characteristics and values }\end{array}$ & $\begin{array}{l}\text { - Chessboard metaphor (Hayes et al., } \\
\text { 1999, pp. 157-158 } \\
\text { - Walking meditation in the context of } \\
\text { values (similar to Segal et al., 2002, pp. } \\
\text { 204-21) }\end{array}$ \\
\hline Session 9 & $\begin{array}{l}\text { - Conversation and role-playing about } \\
\text { the ideal self and role models }\end{array}$ & $\begin{array}{l}\text { - Future perspectives in ten years (similar } \\
\text { to the eulogy exercise, Hayes et al., } \\
\text { 1999, pp. 215-218) } \\
\text { - Letter to the future self }\end{array}$ \\
\hline Session 10 & - $\quad$ Feedback and closure of the group & $\begin{array}{l}\text { - Work with the previously written letters } \\
\text { - } \quad \text { Feedback and closure of the group }\end{array}$ \\
\hline
\end{tabular}

\section{Data analysis}

First, possible missing data was assessed. In case of VLQ, we found some missing data (less than $2 \%$ in total) which were classified as being 'missing completely at random' (Little's Missing Completely at Random Test was not significant) and were replaced with the Expectation-Maximization algorithm. Descriptive analyses were also performed (frequencies, means and standard variations).

Due to the very low sample size, non-parametric tests were used for all outcome data analyses with a confidence interval of 95\%. To assess pre-intervention differences between ACT and TAU, Mann-Whitney U tests were carried out. Post-intervention differences were analyzed in two ways. Possible inter-group differences were assessed using non-parametric analyses of covariance: Quade's tests were performed on each of the post-intervention scores adjusting for the pre-test scores (Quade, 1967). Intra-group changes were evaluated by comparing pre-intervention and post-intervention scores in both conditions with Wilcoxon signed rank tests. Three-month follow-up data was examined identically to the postintervention data. We used Quade's tests for inter-group analyses on three-month follow-up scores, adjusting for the pre-intervention scores. Wilcoxon signed rank tests were applied for pre-intervention and three-month follow-up scores. Differences between post-intervention and three-month follow-up scores were also analyzed with Wilcoxon signed rank tests. Partial eta squared ( $\eta 2)$ were calculated in order to determine effect sizes for Quade's tests. Effect sizes for Wilcoxon signed rank tests were calculated using the $r$ value. (Rosenthal, Cooper, \& Hedges, 1994). Values of .01, .03 and .05 were considered small, medium and large, respectively (Cohen, 1988).

\section{Pre-intervention}

\section{Results}

Participants' demographic characteristics and psychometric data are presented in Table 2 and Table 3, respectively. At onset, all 17 participants were in pre-trial detention charged with 
violent crimes. As a whole, the sample showed elevated levels of depression (four of the inmates had been previously diagnosed with depression), anxiety and psychological inflexibility, together with relatively low levels of values-driven behaviors. Wilcoxon signed rank tests showed no significant differences between the two groups for any of the demographic characteristics and pre-intervention data $(p>.05)$.

Table 2. Characteristics of participants in the TAU and ACT intervention with respect to their age, marital status, children, time in prison, charges and mental health status.

\begin{tabular}{llll}
\hline & & TAU $(n=8)$ & ACT $(n=9)$ \\
& & $M(S D) / n(\%)$ & $M(S D) / n(\%)$ \\
\hline Age & Single & $25.00(6.99 \%)$ & $27.78(9.11)$ \\
Marital status & Married/In a relationship & $5(37.5 \%)$ & $6(66.7 \%)$ \\
\multirow{2}{*}{ Has children } & & $3(37.5 \%)$ & $3(33.3 \%)$ \\
Total time spent in prison in months so far & $12.69(9.32)$ & $3(33.3 \%)$ \\
& Robbery & $4(50.0 \%)$ & $36.61(72.78)$ \\
\multirow{2}{*}{ Charges } & Assault and battery & $2(25.0 \%)$ & $7(77.78 \%)$ \\
& Homicide & $2(25.0 \%)$ & - \\
& Kidnapping & - & $1(11.1 \%)$ \\
Mental health status & Not diagnosed & $6(75.0 \%)$ & $7(11.1 \%)$ \\
& Depression & $2(25.0 \%)$ & $2(22.2 \%)$
\end{tabular}

Notes: TAU = Treatment as usual; ACT = Acceptance and Commitment Therapy; $\mathrm{M}=$ Mean; SD = Standard variation; $\mathrm{n}=$ number of inmates.

\section{Post-intervention}

Mean data are presented in Table 3. Statistical analyses of BDI-SF, BAI and AAQ-II showed no significant differences between ACT and TAU (all non-parametric analyses of covariance: $p>.05$ ). Pre-post intervention differences were also not significant in any of the groups for these variables (all Wilcoxon signed rank tests: $p>.05$ ). In ACT, pre-post differences trended towards significance in the case of BAI ( $p=.080)$, suggesting a slight tendency for the ACT intervention to reduce anxiety.

With regard to VLQ, there were no differences between the two conditions on Importance scores, $\mathrm{p}>.05$, but analysis of Consistency scores showed a significant difference between ACT and TAU, $F(1,8)=9.73, p=.016, \eta 2=.54$. Follow-up analyses indicated that Importance of values did not increase in any of the groups, $p>.05$. Values-consistent behaviors only increased in ACT from pre-intervention $(M d n=64.55)$ to post-intervention $(M d n=70.45)$, $Z=-2.02, p=.043, r=.54$, but not in TAU, $p>.05$. 
Table 3. Results of participants in the BDI-SF, BAI, AAQ-II and VLQ at the different assessment timepoints.

\begin{tabular}{|c|c|c|c|c|c|c|}
\hline & \multicolumn{4}{|c|}{$\begin{array}{l}\text { TAU } \\
M(S D)\end{array}$} & \multicolumn{2}{|l|}{$\begin{array}{l}\text { ACT } \\
M(S D)\end{array}$} \\
\hline & $\begin{array}{l}\text { Pre } \\
n=8\end{array}$ & $\begin{array}{l}\text { Post } \\
n=5\end{array}$ & $\begin{array}{l}\text { 3-month FU } \\
n=3\end{array}$ & $\begin{array}{l}\text { Pre } \\
n=9\end{array}$ & $\begin{array}{l}\text { Post } \\
n=5\end{array}$ & $\begin{array}{l}\text { 3-month FU } \\
n=4\end{array}$ \\
\hline BDI-SF & $12.75(6.54)$ & $9.40(2.88)$ & $12.33(1.52)$ & $12.44(6.44)$ & $9.60(3.78)$ & $9.50(5.00)$ \\
\hline BAI & 23.88 (16.39) & $16.20(15.71)$ & $16.67(7.23)$ & 29.22 (18.34) & $13.60(10.36)$ & 23.75 (20.07) \\
\hline AAQ-II & $23.00(10.46)$ & 17.20 (8.35) & $17.00(7.00)$ & $27.44(8.85)$ & $19.20(4.82)$ & 19.25 (9.98) \\
\hline VLQ Importance & 79.05 (7.52) & $73.53(8.60)$ & 73.33 (11.72) & $76.44(12.70)$ & 78.48 (5.55) & $88.75(8.10)$ \\
\hline VLQ Consistency & 64.39 (15.37) & 50.55 (12.53) & 53.33 (5.77) & 55.39 (32.03) & 70.69 (10.76) & 75.50 (13.63) \\
\hline
\end{tabular}

Notes: TAU $=$ Treatment as usual; ACT $=$ Acceptance and Commitment Therapy; $\mathrm{M}=$ Mean; SD = Standard deviation; BDI-SF = Beck Depression Inventory Short Form; BAI = Beck Anxiety Inventory; AAQ-II = Acceptance and Action Questionnaire-II; VLQ = Valued Living Questionnaire.

Three-month follow-up

Mean data of three-month follow-up are presented in Table 3. Similarly to postintervention, no differences were observed between ACT and TAU on BDI-SF, BAI and AAQII, while adjusting for pre-intervention scores $(p>.05)$. In none of the groups did these measures change significantly from pre-intervention to three-month follow-up ( $p>$.05).

Analyses of VLQ showed no differences between ACT and TAU for Importance scores, but there were significant differences in Consistency scores, $F(1,5)=13.24, p=.015, \eta 2=.73$, suggesting the superiority of ACT. Changes in Consistency and Composite scores however, did not reach a statistically significant level between pre-intervention and three-month follow-up after any of groups, $p>.05$. Finally, there were no significant changes from post-intervention to three-month follow-up in any of the measures, $p>.05$.

\section{Discussion}

This study aimed to compare an ACT-based group intervention with TAU among violence-prone inmates in pre-trial detention. Results showed that TAU did not bring about any changes in the measured variables either at post-intervention, or at three-month follow-up. ACT did not affect levels of depression, anxiety, psychological flexibility and the importance of personal values at post-intervention or at three-month follow-up, but it did enhance valuesconsistent behaviors at post-intervention above and beyond TAU. Significant differences on values-behavior consistency between ACT and TAU were maintained at three-month followup.

It is relevant to discuss the apparent lack of TAU's influence on the measures of the study. There was no wait-list control, thus it is unknown whether these results show that TAU was ineffective or rather it prevented possible declines. On one hand, the inmate population is extremely challenging to work with and treatments sometimes fail to produce measurable effects (e.g., Andrews \& Bonta, 2010; Rice et al., 1992), thus it is quite possible that TAU did not lead to any changes. On the other hand, characteristics of total institutions such as 
correctional facilities may produce a unique set of psychological changes in order to survive (e.g., Goffman, 1961). Previous research has shown that although incarceration may not be harmful to all individuals, in certain circumstances it may be linked to negative psychological effects (e.g., Bukstel \& Kilmann, 1980). This is especially true in the early stages of incarceration, during which psychiatric symptoms may increase (e.g., Harding \& Zimmermann, 1989). It is arguable that TAU may have had some protective effect on these possibly arising problems, but more research is needed to understand the reasons behind the lack of significant changes in TAU.

Data from the ACT-based treatment showed that it did not affect levels of depression and anxiety, only a tendency towards lowered anxiety at post-intervention was observed. These results were not unexpected, as the aim of the ACT intervention was not to diminish symptoms of psychopathology, but to change the relationship with them (e.g., Hayes et al., 2011). ACT proved to be effective in one of its target areas, but ineffective in others. Namely, it did not change levels of psychological inflexibility, but it increased values-consistent actions. Explanations for the lack of increased psychological flexibility may include that the treatment's focal point may have been centered more on the values-based behaviors and less on distancing from problematic mental contents. The results of the increased values-driven actions may be relevant, because ACT sees value-behavior consistency as a key factor in psychological health (e.g., Plumb, Stewart, Dahl, \& Lundgren, 2009). Previous research demonstrated that lower values-behavior correspondence may be linked to lower levels of distress, anxiety, depression and problematic social issues (e.g., Wilson et al., 2011). The increase of values-based actions may be fundamental for the inmates to maintain a fuller, more meaningful life and perhaps contribute to coping better with the prison environment.

This was the first ACT intervention with this extremely problematic sample, thus some important limitations must be considered. The extremely low sample size limits the generalizability of the results. In future studies it would also be beneficial to use more structured sessions, as in the present study the sessions had to be slightly adapted during the intervention. It may be worth assessing whether longer treatments, individual interventions or more experienced therapists would have achieved better results in both conditions. For ethical reasons, we did not use a wait-list control, thus it is unknown whether the interventions may have prevented possible declines. The therapists were not blinded to the study, which may have created a certain bias. Finally, the study has all the limitations of the use of self-report measures: behavioral measures may have shown the effects of the treatments more precisely and hence eliminated the possible dissimulative and manipulative tendencies of the inmates (regarding these tendencies see: Bogan, 1975; Caruso, Benedek, Auble, \& Bernet, 2003; Mobley, 1999). Nonetheless, the study had its strengths: the interventions were conducted on an extremely problematic population by novice therapists and all exercises and metaphors were adapted to them. It was carried out as a relatively early intervention which may have been particularly beneficial for the inmates.

In conclusion, our study showed that a short, group-based ACT intervention implemented by novice therapists may be effective among prisoners in enhancing valuesconsistent actions. It suggests that the basic principles of ACT can be applied to penitentiary contexts and resonate with the core problems of the inmates. Due to the very low sample size, 
these results should be treated with extreme caution and it is necessary to perform further studies to confirm our conclusions.

Funding: This study was funded by the Ministry of National Resources of Hungary (grant number: KAB-ME-14-B-14811).

Ethical approval: All procedures performed in studies involving human participants were in accordance with the ethical standards of the institutional and/or national research committee and with the 1964 Helsinki declaration and its later amendments or comparable ethical standards.

Informed consent: Informed consent was obtained from all individual participants included in the study.

\section{References}

A-Tjak, J. G., Davis, M. L., Morina, N., Powers, M. B., Smits, J. A., \& Emmelkamp, P. M. (2015). A meta-analysis of the efficacy of acceptance and commitment therapy for clinically relevant mental and physical health problems. Psychother Psychosom, 84(1), 30-36.

Amrod, J., \& Hayes, S. C. (2013). Act for the Incarcerated. Forensic CBT (pp. 43-65): John Wiley \& Sons.

Andersen, H. S. (2004). Mental health in prison populations. A review-with special emphasis on a study of Danish prisoners on remand. Acta Psychiatr Scand Suppl(424), 5-59.

Andrews, D. A., \& Bonta, J. (2010). Rehabilitating criminal justice policy and practice. Psychology, Public Policy, and Law, 16(1), 39.

Andrews, D. A., Zinger, I., Hoge, R. D., Bonta, J., Gendreau, P., \& Cullen, F. T. (1990). Does correctional treatment work? A clinically relevant and psychologically informed metaanalysis. Criminology, 28(3), 369-404.

Bach, P., \& Hayes, S. C. (2002). The use of acceptance and commitment therapy to prevent the rehospitalization of psychotic patients: a randomized controlled trial. Journal of Consulting and Clinical Psychology, 70(5), 1129-1139.

Beck, A. T., \& Beck, R. W. (1972). Screening depressed patients in family practice. A rapid technic. Postgraduate Medicine, 52(6), 81-85.

Beck, A. T., Epstein, N., Brown, G., \& Steer, R. A. (1988). An inventory for measuring clinical anxiety: psychometric properties. Journal of Consulting and Clinical Psychology, 56(6), 893.

Berzins, L. G., \& Trestman, R. L. (2004). The development and implementation of dialectical behavior therapy in forensic settings. International Journal of Forensic Mental Health, 3(1), 93-103.

Bogan, J. B. (1975). Client dissimulation: A key problem in correctional treatment. Federal Probation, 39, 20.

Bond, F. W., Hayes, S. C., Baer, R. A., Carpenter, K. M., Guenole, N., Orcutt, H. K., \& Zettle, R. D. (2011). Preliminary psychometric properties of the Acceptance and Action Questionnaire-II: a revised measure of psychological inflexibility and experiential avoidance. Behaviour Therapy, 42(4), 676-688. d 
Bowen, S., Witkiewitz, K., Dillworth, T. M., Chawla, N., Simpson, T. L., Ostafin, B. D., \& Marlatt, G. A. (2006). Mindfulness meditation and substance use in an incarcerated population. Psychology of Addictive Behaviors, 20(3), 343.

Bukstel, L. H., \& Kilmann, P. R. (1980). Psychological effects of imprisonment on confined individuals. Psycholical Bulletion, 88(2), 469.

Caruso, K. A., Benedek, D. M., Auble, P. M., \& Bernet, W. (2003). Concealment of psychopathology in forensic evaluations: a pilot study of intentional and uninsightful dissimulators. Journal of the American Academy of Psychiatry and the Law Online, 31(4), 444-450.

Cohen, J. (1988). Statistical Power Analysis for the Behavioral Sciences: Taylor \& Francis.

Eisenbeck, N., Szondy, M., Schlosser, K., \& Szabo-Bartha, A. (under preparation-a). The Hungarian version of the Acceptance and Action Questionnaire (AAQ-II).

Eisenbeck, N., Szondy, M., Schlosser, K., \& Szabo-Bartha, A. (under preparation-b). The Hungarian version of the Valued Living Questionnaire (VLQ).

Eurostat: Crime and criminal justice database. (2015). Retrieved December 3, 2015, from http://ec.europa.eu/eurostat/web/crime/database

Forman, E. M., Herbert, J. D., Moitra, E., Yeomans, P. D., \& Geller, P. A. (2007). A randomized controlled effectiveness trial of acceptance and commitment therapy and cognitive therapy for anxiety and depression. Behaviour Modification, 31(6), 772-799.

González, M. A., García, P. F., Lamelas, F. R., \& Lanza, P. V. (2014). Long-term outcomes of Acceptance and Commitment Therapy in drug-dependent female inmates: A randomized controlled trial. International Journal of Clinical and Health Psychology, 14(1), 18-27.

Harding, T., \& Zimmermann, E. (1989). Psychiatric symptoms, cognitive stress and vulnerability factors. A study in a remand prison. The British Journal of Psychiatry, 155(1), 36-43.

Harvey, J., \& Smedley, K. (2010). Psychological Therapy in Prisons and Other Secure Settings. New York: Willian.

Hayes, S. C., Luoma, J. B., Bond, F. W., Masuda, A., \& Lillis, J. (2006). Acceptance and commitment therapy: Model, processes and outcomes. Behaviour Research and Therapy, 44(1), 1-25.

Hayes, S. C., Pistorello, J., \& Levin, M. E. (2012). Acceptance and commitment therapy as a unified model of behavior change. The Counseling Psychologist, 40(7), 976-1002.

Hayes, S. C., Strosahl, K., \& Wilson, K. G. (1999). Acceptance and Commitment Therapy: An Experiential Approach to Behavior Change: Guilford Press.

Hayes, S. C., Strosahl, K. D., \& Wilson, K. G. (2011). Acceptance and Commitment Therapy, Second Edition: The Process and Practice of Mindful Change: Guilford Publications.

James, D. J., \& Glaze, L. E. (2006). Mental health problems of prison and jail inmates: US Department of Justice, Office of Justice Programs, Bureau of Justice Statistics Washington, DC.

Johns, L. C., Oliver, J. E., Khondoker, M., Byrne, M., Jolley, S., Wykes, T., \& Morris, E. M. (2015). The feasibility and acceptability of a brief Acceptance and Commitment Therapy (ACT) group intervention for people with psychosis: The 'ACT for life' study. $J$ Behaviour Therapy and Experimental Psychiatry, 50, 257-263. 
Khodayarifard, M., Shokoohi-Yekta, M., \& Hamot, G. E. (2010). Effects of individual and group cognitive-behavioral therapy for male prisoners in iran. International Journal of Offender Therapy and Comparative Criminology, 54(5), 743-755.

Kohtala, A., Lappalainen, R., Savonen, L., Timo, E., \& Tolvanen, A. (2015). A four-session acceptance and commitment therapy based intervention for depressive symptoms delivered by masters degree level psychology students: a preliminary study. Behavior and Cognitive Psychotherapy, 43(3), 360-373.

Landenberger, N., \& Lipsey, M. (2005). The positive effects of cognitive-behavioral programs for offenders: A meta-analysis of factors associated with effective treatment. Journal of Experimental Criminology, 1(4), 451-476.

Lanza, P. V., \& González, M. A. (2013). Acceptance and Commitment Therapy for drug abuse in incarcerated women. Psicothema, 25(3), 307-312.

Lanza, P. V., García, P. F., Lamelas, F. R., \& González, M. A. (2014). Acceptance and commitment therapy versus cognitive behavioral therapy in the treatment of substance use disorder with incarcerated women. Journal of Clinical Psychology, 70(7), 644-657.

Lappalainen, R., Lehtonen, T., Skarp, E., Taubert, E., Ojanen, M., \& Hayes, S. C. (2007). The impact of CBT and ACT models using psychology trainee therapists: a preliminary controlled effectiveness trial. Behaviour Modificartion, 31(4), 488-511.

Lipsey, M., Landenberger, N. A., \& Wilson, S. J. (2007). Effects of Cognitive-Behavioral Programs for Criminal Offenders: A Systematic Review. Campbell Systematic Reviews, 3(6).

Luciano, C., Ruiz, F. J., Vizcaíno-Torres, R., Sánchez, V., Gutiérrez-Martínez, O., \& LópezLópez, J. (2011). A relational frame analysis of defusion interactions in acceptance and commitment therapy. A preliminary and quasi-experimental study with at-risk adolescents. International Journal of Psychology and Psychological Therapy, 11(2), 165-182.

Luoma, J. B., \& Vilardaga, J. P. (2013). Improving therapist psychological flexibility while training acceptance and commitment therapy: a pilot study. Cognitive Behavior and Therapy, 42(1), 1-8.

Mobley, M. (1999). Psychotherapy with criminal offenders. The Handbook of Forensic Psychology, 2, 603-639.

Oliver, J. E., Joseph, C., Byrne, M., Johns, L. C., \& Morris, E. M. J. (2013). Introduction to Mindfulness and Acceptance-based Therapies for Psychosis Acceptance and Commitment Therapy and Mindfulness for Psychosis (pp. 1-11): John Wiley \& Sons.

Öst, L.G. (2008). Efficacy of the third wave of behavioral therapies: A systematic review and meta-analysis. Behaviour Research and Therapy, 46(3), 296-321.

Öst, L. G. (2014). The efficacy of Acceptance and Commitment Therapy: An updated systematic review and meta-analysis. Behaviour Research and Therapy, 61, 105-121.

Perczel Forintos, D., Sallai, J., \& Rózsa, S. (2001). A Beck-féle Reménytelenség Skála Pszichometriai vizsgálata. Psychiatria Hungarica, 6, 632-643.

Plumb, J. C., Stewart, I., Dahl, J., \& Lundgren, T. (2009). In Search of Meaning: Values in Modern Clinical Behavior Analysis. The Behavior Analyst, 32(1), 85-103. 
Powers, M. B., Zum Vörde Sive Vörding, M. B., \& Emmelkamp, P. M. (2009). Acceptance and commitment therapy: A meta-analytic review. Psychotherapy and Psychosomatics, 78(2), 73-80.

Quade, D. (1967). Rank analysis of covariance. Journal of the American Statistical Association, 62(320), 1187-1200.

Rice, M. E., Harris, G. T., \& Cormier, C. A. (1992). An evaluation of a maximum security therapeutic community for psychopaths and other mentally disordered offenders. Law and Human Behavior, 16(4), 399.

Rosenthal, R., Cooper, H., \& Hedges, L. (1994). Parametric measures of effect size. The Handbook of Research Synthesis, 231-244.

Rózsa, S., Szádóczky, E., \& Füredi, J. (2001). A Beck Depresszió Kérdõív rövidített változatának jellemzõi a hazai mintán. Psychiatria Hungarica, 16(4), 379-397.

Segal, Z. V., Williams, J. M. G., \& Teasdale, J. D. (2002). Mindfulness-based Cognitive Therapy for Depression: A New Approach to Preventing Relapse: Guilford Press.

Stafford-Brown, J., \& Pakenham, K. I. (2012). The Effectiveness of an ACT Informed Intervention for Managing Stress and Improving Therapist Qualities in Clinical Psychology Trainees. Journal of Clinical Psychology, 68(6), 592-513.

Wilson, D. B., Bouffard, L. A., \& MacKenzie, D. L. (2005). A quantitative review of structured, group-oriented, cognitive-behavioral programs for offenders. Criminal Justice and Behavior, 32(2), 172-204.

Wilson, K. G., \& Luciano, M. C. (2002). Terapia de aceptación y compromiso (ACT): un tratamietno conductual orientado a los valores. Madrid: Pirámide.

Wilson, K. G., Sandoz, E. K., Kitchens, J., \& Roberts, M. (2011). The Valued Living Questionnaire: Defining and measuring valued action within a behavioral framework. The Psychological Record, 60(2), 4. 